\title{
Exploratory Study of the Character Font in the Format Design
}

\author{
Bing Liu ${ }^{1, \text { a }}$, Fu Liu ${ }^{2, \text { b* }}$ \\ ${ }^{1}$ Academy of Fine Arts, Northeast Normal University, Changchun130024, China \\ aice8515@163.com, bfuliu6286@163.com
}

\begin{abstract}
This research from the layout of the font design, and how to get the harmony unity of font and format design are discussed, through analysis of the current situation of the development of format design, the character and expression of font are studied. The research shows, Character font is an important part of format design, to strengthen the interactive relationship between font form and content, can make fonts full of unique expressive power. Combined with the theme of the book, adjusting the order of the font and reading direction, can make the audience quickly and clearly access to information, experience the sense of intimacy and happiness.
\end{abstract}

Keywords: Character Font; Font design; Format design; Exploratory study

\section{Introduction}

The era of pluralistic cultural information, font is the most intuitive and effective visual communication elements, by means of fast and large print media, to disseminate information quickly to all parts of the world. Font is not only the carrier of information, but also the sign system with visual recognition, font can not only convey information, but also convey feelings; different font size will give people different visual experience. The design of the character font is an indispensable part of the modern bookbinding and format, and has a direct impact on the visual communication effect [1].

The main function of format design is to construct the visual bridge between the reader and the book, in today's book binding design works, font as an important element in the format design has not been given due attention, in the works, the arrangement of font is disordered, and the lack of correct visual order in space, so that it is difficult to accurately convey the contents of the book, but also is not good for reader to read books effectively [2].

\section{Fonts and Format Design}

Font is the visual form of language, it breaks through the limitation of time and space and becomes a tool for human to transmit information, in the format design can be used as an independent unit, can also be a continuous line, assembly forming. In the design of font and format, the plasticity of the font enriches the expressive power of the layout and the language of emotion, in the transmission of information at the same time; the font has become an inspiration, creativity, aesthetic, fashion, and artistic factors $[3,4]$.

In order to meet the visual requirements of readers, the font in the format design break the shackles of traditional thinking. There are many kinds of font arrangement, in which free arrangement is widely used. Books to be able to understand the designer to convey the "information", through reading, understanding of the designer's creativity, innovative ideas and design practice, and constantly stimulate the designer's creative inspiration, expand ideas, open up new areas of format design. The main function of the font is to convey the author's intention and emotion, in order to produce communication and resonance; this requires that the font have a clear visual image, in order to achieve a good appeal. Therefore, the first task is to make the text easy to understand and accurately express the design theme, font design to serve the work, in line with the style of the works, with beautiful and dignified, cheerful, reflected light, vigorous and simple, other wonderful personality. In the process of visual communication, font is one of the essential elements of the 
overall picture and layout; it must have a good visual beauty and enjoyment, clever combination in order to accurately convey emotions [5].

Font format design is more important is the function of the font to convey information, in addition to our understanding of the font itself, its own structural characteristics of the format design is an indispensable material. So we must pay special attention to the font size, area, thickness and stroke combined relationship, it is necessary to study the structure of the font and find the internal relations between the fonts. The font after designer design, easier to identify and memory, to facilitate the format of the page, so that font and format more personality, but also give people a visual pleasure. The image of the font should strive to be beautiful, and through the layout of the artistic aesthetic, so that the content of the information to be fully reflected $[6,7]$.

Although the font occupies a certain visual space, and through a special form of composition, to express a certain degree of visual transmission, but it is not only a pure expression of the visual image, the font has the dual function of information transmission and display visual image, therefore, if only in the form of purely visual language performance, while ignoring the artistic appeal of the font, or only focus on the content of the transmission of memory, ignoring the influence of the font, this kind of design works are incomplete and failure.

\section{Exploratory Study of the Character Font in the Format Design}

The artist's creation is the artist's use of materials, the book is a kind of carrier of information dissemination, and the font is the most important content of the information dissemination of books. By using a combination of font "orthomorphic" and "anti - orthomorphic", the layout shows a unique artistic charm, in the process of writing the font, we should pay attention to the combination of the arrangement of the front and the theme of the book, can not be separated from the design of the central idea, to achieve the organic combination of form and meaning, different forms of font will give people a different visual experience.

\subsection{Research on Format Design: Font "Orthomorphic" and "Anti - orthomorphic" Expression} Application of "orthomorphic" and "anti - orthomorphic" fonts, it is one of the most popular and most innovative book binding design, in the "orthomorphic" font, font settings, variable line spacing kerning, multi angle arrangement, application of color and point line connection, all occupies a position in the richly endowed by nature in format design, so that the audience at the same time access to information to achieve spiritual enjoyment and comfort. "Anti - orthomorphic" fonts format appears, it makes the reader change the reading perspective in the traditional sense, and bring the different visual experience, to allow the reader to produce a more intense interest in the work.

From the point of view of comfortable reading, in the format design, the character of the positive and negative font should be applied in many aspects, taking into account the overall content of the book, that is, and the theme of thinking. To make a thoughtful book with depth, after a series of investigations and studies, to determine the center of the book, from the overall perspective of the overall design, combined with the format design method, with the form of text and pictures in the dissemination of the idea of reading books.

As an expression of format design, the "orthomorphic" and "anti - orthomorphic" fonts, make reading appeared a kind of unexpected feelings, "Anti - orthomorphic" fonts as a text graphics, that is, the dissemination of information and visual impact, however, the design of the fonts on "orthomorphic" and "anti - orthomorphic", it should be both opposite and unified, so that the style of books have a strong contrast, and closely linked to the theme.

\subsection{Research on Format Design: Changes in the Direction of Text Reading}

In the process of book format, the reading order of font is from right to left, changes in the direction of text reading, to some extent, hinder the smooth reading, but this style of font design can attract readers, to enable the reader to see this book more interest, more desire to explore the information content of the text. The reader can understand the content of the text through the reverse layout, and at the same time reading, in-depth understanding of the performance of the ideas and content. Factual 
proof, readers are willing to accept this form of arrangement, better reflect the theme of the book and the idea of text typesetting direction to achieve unity of opposites.

In book design, designers to "open" as a big theme, with the social status, philosophy, religion and other aspects of research and design, the designer set the central idea as the two sides of the person and the thing, dig the other side, and then reflect the unity of opposites. Combined with the overall idea of books, graphics and fonts, to make a strong contrast to the style of the book, clearly showing the central idea. Bookbinding, text font in the format design is a very important issue, different fonts have different style and temperament, even if the same font, different versions will have different aesthetic taste. Therefore, the choice of font must conform to the inner spirit of the text, in this way; the overall format design can be combined with the text content. "Meaningful form" has become an obvious trend in the format design of books, it is always in the form of a new visual display in front of us, and constantly influence our thinking and way of life.

Only the text without pictures of the book, there is no charm, will be defeated by the network, books should be developed in a rich and lively manner, book design should be combined with the designer's understanding of the content, targeted for font design and image add, in the interest of reading and interaction efforts to attract readers, not just in the material effort.

\section{Conclusions}

Character font, as a way of visual communication in format design, it not only gives the aesthetic appearance of the font, but also expands the function of the font to a new field, the comprehensive application of "orthomorphic" and "anti - orthomorphic" fonts, making the layout presents a unique artistic charm, it is one of the most popular and most innovative book binding design, so that the audience at the same time access to information to achieve spiritual enjoyment and comfort, so that the audience at the same time access to information to achieve spiritual enjoyment and comfort, so that readers have a greater interest in the work. The format of the font form has the accuracy of information communication, but also has new originality and overall artistic, let the audience in the fast clear access to information at the same time, realize the intimate and pleasant feeling in the process of reading.

\section{Corresponding Author}

Fu Liu, Associate Professor, Northeast Normal University, CHINA, fuliu6286@163.com.

\section{Acknowledgement}

The authors gratefully thank the financial support by Research Project in Jilin Social Science Fund Project (2013BS14); Youth fund of Northeast Normal University in philosophy and social science school projects (12QN017); Youth fund of Northeast Normal University in philosophy and social science school projects-art project (MSZX2012-01).

\section{References}

[1] Zhijun Du: A Study on the Preference According to Chinese Character Calligraphy with Emotional, A Journal of Brand Design Association of Korea, Vol. 15(1), p.27-38, 2017

[2] Liu Na, Yu Ruifeng, Zhang Yunhong: Effects of Font Size, Stroke Width, and Character Complexity on the Legibility of Chinese Characters, Human Factors and Ergonomics in Manufacturing \& Service Industries, Vol. 26(3), p.381-392, 2016.

[3] Yang Xinzhong, Li Cailin: The Application of the "Combine Font" in the Design of Chinese Characters Logo, Packaging Engineering, Vol.37 (12), p.67-71, 2016. 
[4] Richard Herriott: Are Inclusive Designers Designing Inclusively? An Analysis of 66 Design Cases, The Design Journal, Vol.16 (2), p.138-158, 2015.

[5] Renée Cheng: Designers Designing Design Education, Journal of Architectural Education, Vol.68 (1), p.12-14, 2014.

[6] James Hartley: Readers as Text Designers: Personalizing the Layout of Text, Innovations in Education \& Teaching International, Vol.36 (4), p.346-350, 2006.

[7] Mary C. Dyson: Where Theory Meets Practice: A Critical Comparison of Research into Identifying Letters and Craft Knowledge of Type Design, The Design Journal, Vol.16, p. 271-294, 2013. 